\title{
Development of the Stage Flow Relations for a Tropical Watershed
}

\author{
Shahram Khosrowpanah ${ }^{1}$, Mark Alan Lander ${ }^{2}$, Ujwalkumar Dashrath Patil ${ }^{1,}$ * \\ ${ }^{1}$ School of Engineering, University of Guam, Mangilao, Guam \\ ${ }^{2}$ Water and Environmental Research Institute, University of Guam, Mangilao, Guam
}

Email address:

patilu@triton.uog.edu (U. D. Patil)

${ }^{*}$ Corresponding author

\section{To cite this article:}

Shahram Khosrowpanah, Mark Alan Lander, Ujwalkumar Dashrath Patil. Development of the Stage Flow Relations for a Tropical Watershed. Hydrology. Vol. 7, No. 3, 2019, pp. 38-45. doi: 10.11648/j.hyd.20190703.11

Received: August 16, 2019; Accepted: September 4, 2019; Published: September 19, 2019

\begin{abstract}
The effluent discharge from wastewater treatment plants can permeate through the ground and become a major source of contaminant to ecosystems and water bodies. These toxic contaminants can transport and find a way to the ocean via underground streams harming the aquatic life and promoting algal blooms. This paper presents meteorological and hydrological data collection and analysis to better understand the characteristics of the effluent discharge from the wastewater treatment plant and receiving water in Toguan watershed on the Island of Guam so as to support future regulatory discussions regarding modification of permit conditions and/or water quality standards to achieve compliance. Hydrological data such as rainfall, turbidity and stream level were collected over a period of two years. Crossflow measurements for two stations, one downstream, the other upstream of the effluent discharge point were collected bi-weekly, except at times of very low flow or dangerously high storm runoff in the stream. To better understand the behavior of the Toguan River sub-watersheds, aerial photos were taken from a single-engine Cessna aircraft. By analyzing the collected hydrological data, the relationships among the stream level, volume discharge and rainfall, were developed. The manually collected crossflow data allowed for the calculation of a rating curve for the Toguan River. This effort was somewhat hampered by prolonged drought conditions during roughly half of the period of data collection that severely limited the amount of crossflow measurements taken at high stage heights. The continuous measurement of stream level and rainfall allowed for a more comprehensive analysis of the relationship between the stage height and rainfall. Finally, a complimentary stream stage height short-term prediction scheme was developed using a routing model, and refinements to the stream flow discharge curve using a simple model for open channel flow is also presented. A further benefit of the study was the establishment of a baseline for the hydrologic conditions of the Toguan watershed which can be used to assess changes related to any future improvements to the wastewater treatment plant operations or other significant developments within this watershed.
\end{abstract}

Keywords: Watershed, Hydrological Data, Turbidity, Stage Discharge Curve, Watershed Management Practices

\section{Introduction}

Wastewater treatment is a process used to convert wastewater into an effluent that can be either returned to the water cycle with minimal environmental issues or reused [13]. In general, this treatment includes removing impurities from water being treated; and some methods of treatment are applicable to both water and wastewater. A wastewater treatment plant (WWTP) may be used to manage human waste, solid waste, sewage, storm water, and for water treatment. By-products from wastewater treatment plants, such as screenings, grit and sewage sludge may also be treated in the treatment plant. If the wastewater is predominantly from municipal sources (households and small industries) it is called sewage and its treatment is called sewage treatment. However, if the efficiency of WWTP is not effective then the water resources could be harmed by the pollution from disposed effluent $[2,3]$.

The Toguan Watershed (Figures 1 and 2) is comprised of dense forest, some savanna, some wetlands at the lower reaches, and a small amount of badlands along the 
surrounding ridges. The village of Merizo is situated along the coast south of the Toguan watershed and the village of Umatac is to the north (Figure 2). There is little development within this watershed, with the exception of residential coastal developments along the island's primary coastal road and the Guam Water Authority (GWA) wastewater treatment plant (WWTP). Efforts are being made for upgrading the wastewater infrastructure to mitigate impacts to the environment. Since then there is an increasing interest concerning hydrology of the areas affected. Furthermore, there have been substantial changes in land cover over time that need to be taken into account in future watershed restoration efforts [4].

In addition, Guam coastal resource managers continue to assess areas that could benefit from watershed "restoration $[5,6]$." For a "restoration" project to be deemed successful it is of great importance to determine the physical condition of the watershed prior to the "restoration" and establish the nature of the pristine condition toward which the "restoration" aims. The Toguan watershed is an ideal site to establish the physical conditions of a watershed that, while not necessarily pristine with respect to pre-human activity, the interior portion of the watershed is among the most pristine areas existing on Guam. A further benefit of the study would be to establish a baseline for the Toguan watershed for comparison to any future restoration operations or other significant developments within this watershed.

The Toguan wastewater treatment plant (WWTP) facility uses a low technology terraced overland flow system to purify the wastewater. The overland flow treatment of wastewater involves the application of the wastewater to a sloping terrace (Figure 1) of impervious or relatively impervious soil which is planted in a grass crop compatible with heavy irrigation. Previous testing results have shown that the effluent into the Toguan River is not able to achieve the effluent discharge requirement established by the National Pollutant Discharge Elimination System (NPDES) permit [7]. GWA has thus initiated an action plan that includes multiple improvement projects within the collection system and at the WWTP. The data collection and analysis from this research paper will assist GWA to better understand the characteristics of the effluent discharge and receiving water, as well as to support future regulatory discussions regarding modification of permit conditions and/or water quality standards to achieve compliance.

This paper describes the logistics and methods used to collect meteorological and hydrological data for the site. The paper also presents the results of our analysis of the collected data with an aim to better understand the characteristics of the effluent discharge from the wastewater treatment plant and receiving water in Toguan watershed in Guam and also to support future regulatory discussions regarding modification of permit conditions and/or water quality standards to achieve compliance. Rainfall, turbidity, and stream level were continually measured at 15-minute intervals over a period of two years. Crossflow measurements for two stations (Figure 2) - R1 (downstream of the effluent discharge of the receiving water) and R2 (upstream of the effluent) were collected bi-weekly, except during the numerous times of very low (or no) flow or during times of dangerously high water in the stream. To better understand the behavior of the Toguan River's subwatersheds, aerial photos were taken from a single-engine Cessna aircraft. The manually collected crossflow data allowed for the calculation of a rating curve for the Toguan River. This effort was somewhat hampered by prolonged drought conditions during roughly half of the period of data collection that severely limited the amount of crossflow measurements taken at high stage heights. The continuous measurement of stream level and rainfall allowed for a more comprehensive analysis of the relationship between the stage height and rainfall.

By analyzing the collected hydrological data, the relationships among the stream level, volume discharge and rainfall were developed. A complimentary stream stage height short-term prediction scheme was developed using a routing model. Refinements to the stream flow discharge curve were made using a simple model for open channel flow. A further benefit of the study was the establishment of a baseline for the hydrologic conditions of the Toguan watershed which can be used to assess changes related to any future improvements to the wastewater treatment plant operations or other significant developments within this watershed.

\section{Methods}

\section{Meteorological Setting}

One data logging rain gauge was installed at the upslopeend of the terraces in the Toguan watershed (Figure 2). Three level loggers and a turbidimeter were placed along the course of the Toguan River. Continuous measurements of rainfall, water level and turbidity measurements were obtained from November 2015 through December 2016. Manual measurements of river volumetric flow were obtained at irregular intervals in an attempt to catch a wide variety of flow conditions from which the stage-flow relationships could be derived.

The period of observation (November 2015 to December 2016) was unusually dry because of the occurrence of El Niño during 2015. The 2015/16 El Niño was one of the strongest in the historical record, taking its place in the top three, along with the epic El Niño events of 1982/83 and $1997 / 98$. The rainfall on Guam during the 2015/16 El Niño event proceeded in a typical fashion, with wild wet conditions during January to August 2015, followed by very dry conditions that began in the fall of 2015 and continued through the first half of 2016 (Figure 3). Average to aboveaverage rainfall occurred from August 2016 through the end of the year (Figure 3).

Monthly amounts of rainfall were reduced through much of 2016 (versus average, and as compared with 2015). The daily rainfall amounts also had a similar distribution as the monthly rainfall: during 2015 there were four occurrences of 
24-hour rainfall in excess of 4 inches, and during 2016 there were none. In addition to the rain recordings from the rain gauge located at the terrace field, daily rainfall was also recorded at a site along the ridge line of Guam's southern mountains, about 2 miles to the north of the Toguan Watershed. The peak 24-hour value of 10 inches occurred on the 15th of August, 2015, as Tropical Storm Goni was passing to the north of the island. This heavy rainfall caused very high water in the Toguan River (over head-high) that washed out a newly installed river staff gauge. The instrumentation for the study was not in-place at the time of this event.

In summary, the weather during the period of study was rather unremarkable. It was quite dry through at least the first half of the study. And, in spite of increased monthly rainfall in the second half of 2016, there were no exceptional shortperiod (hourly and daily) rainfall events. The largest manual measurement of flow volume was obtained on 28 December 2015 when the stream stage height was just over knee-deep.

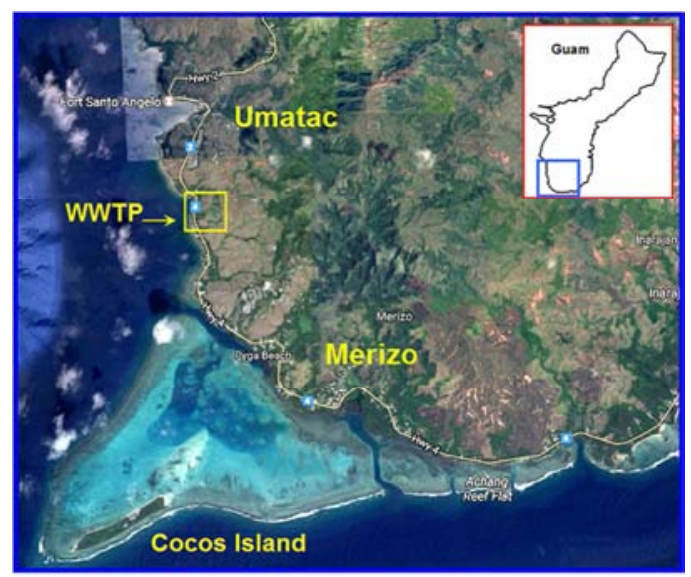

Figure 1. Aerial view of the site in southwestern Guam of the UmatacMerizo wastewater treatment plant.

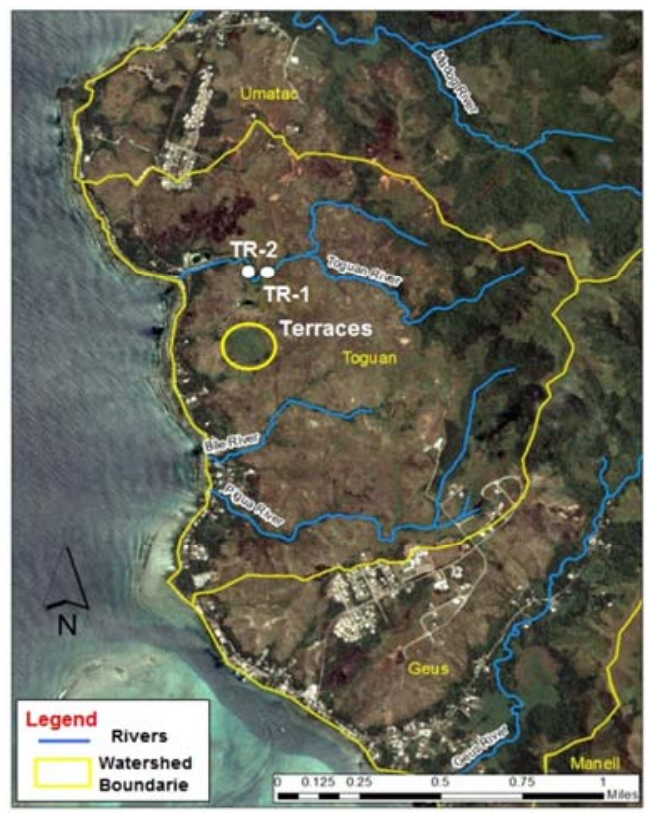

Figure 2. The Toguan river watershed with data collection sites indicated.

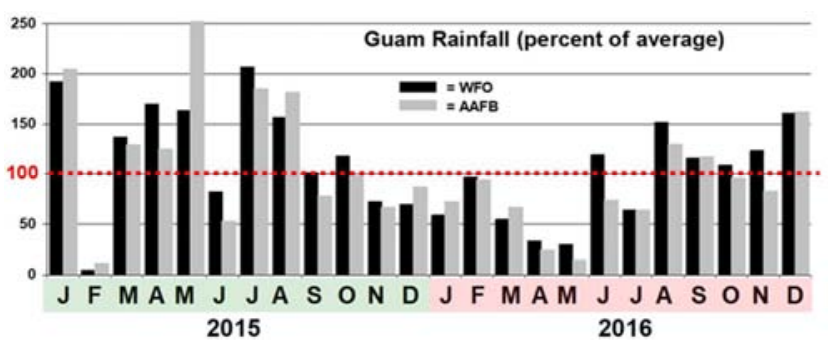

Figure 3. A time series of Guam rainfall during 2015 and 2016. Wet and wild conditions through the first half of 2015 gave way to very dry conditions that persisted through the first half of 2016. Plotted values are the monthly rainfall as a percent of average for both the Tiyan Guam Weather Forecast Office (WFO) and Andersen Air Force Base (AAFB).

\section{Site Selection Criteria}

The sites for data collection were chosen for ease of access and optimal placement for the designated purpose. The rain gauge installed in the Toguan watershed was placed on the uphill side of the terraces of the WWTP (Figure 4). A utility road runs uphill through the middle of the terrace fields and is accessible by ordinary two-wheel drive autos and trucks. Another rain gauge used in the project was already in-place along the Southern Mountain ridge line about 2 miles to the north of the WWTP. This gauge has been in continuous use since 2005 when it was installed for a water and environmental research institute (WERI) project to study the Ugum River on the eastern side of Guam. A third rain gauge near the study site is located at the Merizo mayor's office (about 2 miles to the southeast of the WWTP). The Merizo gauge is one of four automated weather observing stations operated on Guam by the Tiyan weather forecast office (WFO) for general weather and hydrologic forecast support. Unfortunately, this gauge failed early-on in the project period and was out-of-service for nearly all of the project duration. Level loggers were installed upstream and downstream of the wastewater outfall into the Toguan River.

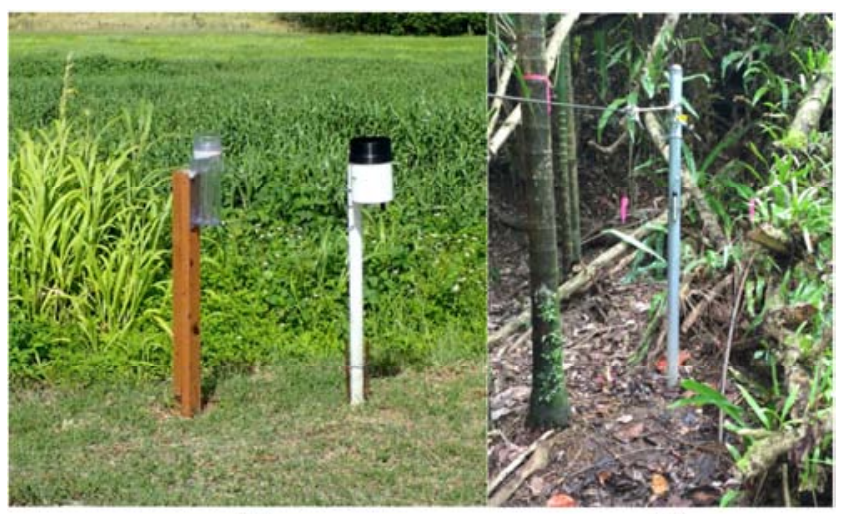

(a)

(b)

Figure 4. (a) Rain gauges located on-site at the uphill side of the terrace field; and (b) Level Logger to measure atmospheric pressure.

\section{Field On-site Data Collection}

The Toguan River reconnaissance and site planning for monitoring equipment installation was completed in October 2015. Continuous rainfall data (at one-minute resolution) was 
obtained at the site and at another site situated on the ridge line of the southern mountains about 2 miles north of the site (Figure 4). Water level changes of the Toguan River were electronically logged with stream level loggers, with the data manually downloaded monthly at two sites (designated TR1 and TR2) in the River since November 9, 2015 (Figure 2). The two stream level loggers were anchored in the stream bed (one at site TR1 and the other at site TR2) to measure the (Figures 2 and 5). A third level logger was installed on the stream bank (Figures 4 ) to measure the atmospheric pressure at the site, which was subtracted from the pressure readings made in the stream to yield the water depth. The water level and atmospheric pressure readings were electronically logged continually at 15-minute intervals starting on November 12, 2015. Electronically logged turbidity readings were manually downloaded during each site visit since December 7, 2015. Manual stream flow measurements were obtained biweekly beginning in October 2015, with special trips made to acquire storm-induced higher flows.

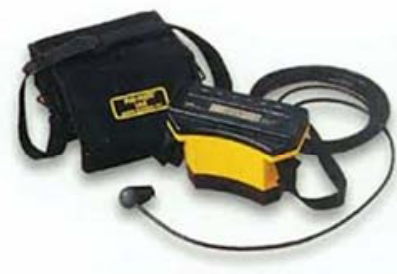

(a)

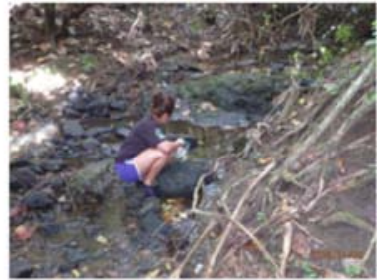

(b)
Figure 5. (a) Marsh-McBirney "Flow-Mate" flow meter; and (b) Research assistant installing a level logger in Toguan river.

\subsection{Rainfall Data}

One electronically recording tipping bucket rain gauge was installed on site at the top of the terrace field (Figure 4). The electronic rain gauge allows rainfall to be measured at a precision of 1.5 seconds (the lock-out time for possible rapid double tips from bucket bounce). Each bucket tip occurs for every 0.01 inch of rain. Thus, the maximum rainfall that could potentially be recorded by this gauge is 0.01 inches every 1.5 seconds, or 0.40 inches in one minute. In over 20years of using such rain gauges on Guam, water and environmental research institute (WERI) scientists have noted that the highest 1 -minute rainfall was 0.19 inches during the height of typhoon Pongsona (December 2002). The shortest interval observed between successive bucket tips was three seconds, also occurring in typhoon Pongsona. Each tip of the bucket occurs when an amount of water equivalent to 0.01 inches of rain that has passed through the funnel and into the bucket. A magnetic switch is activated as the bucket tips on its pivot to discharge the water, sending a brief charge spike to the data logger which then uses its internal clock to timestamp the tip. The data logger can record time stamps for 8000 tips, or 80 inches of rainfall before it begins to over-write old data. The data can be downloaded onto a field shuttle or via a base station attached to a lap-top computer. In either scenario, the logger clock is reset, and the logger data registers are cleared. A complete two-year time series of the rainfall for the Toguan site is contained in Figure 3.

\subsection{Crossflow Data}

The streamflow volume can be computed from the streamflow velocities manually obtained using a MarshMcBirney flow Mate portable flow meter and a tape measure. The tape measure was tensed horizontally across the stream, and measurements of the flow velocity were obtained at 6-inch intervals across the entire width of the stream (at both sites TR1 and TR2). The individual taking the flow readings slowly traverses the stream and reads the flow velocity that is shown on an LCD display on the portable control unit attached by wire to the flow measuring head. In practice, one individual stood in the stream and made the flow measurements and another individual stood to the side and recorded the information. Flow readings are not logged by the control unit but entered manually into a notebook. Later, the flow readings, coupled with the known stream profile, were used to compute the flow volume.

\subsection{Aerial Photogrammetry}

In order to complement existing maps and satellite images of the Toguan watershed, a small plane was rented from Trend Vector Aviation. The single-engine Cessna aircraft seats four (including the pilot). On a clear morning, the WERI project team flew low over the Toguan watershed to obtain as many pictures as possible to get a detailed look at the Toguan watershed and the infrastructure of the WWTP (Figure 6). The photos thus obtained were of importance to establish the baseline conditions of the watershed prior to major capital improvements at the WWTP, and also for use in determining the land-use parameters for GIS applications.

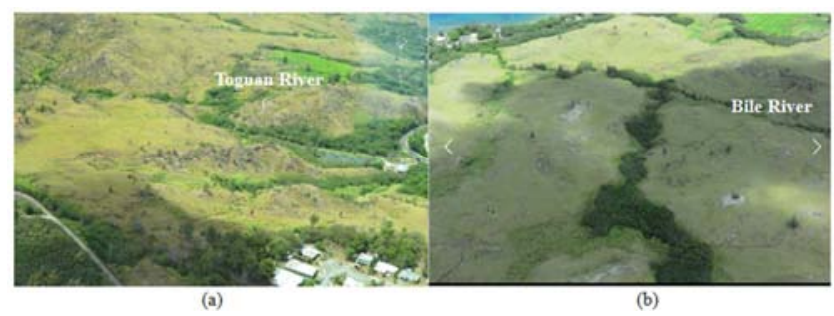

Figure 6. Aerial Photo of (a) Toguan River; and (b) Bile river.

\subsection{Stream Flow Computations}

For each acquisition of the cross section of flow velocity at the river sites TR1 and TR2, a computation of total volume of flow was made using a simple method. Since the flow was measured at 6-inch intervals across the width of the stream, a set of rectangles was constructed along the stream profile (Figure 7), with the measured flow lying at the center of each rectangle. An algorithm created in MS Excel automatically calculated the incremental cross section area and segment flow volume 
from which the total flow, Q, of the stream was determined (Figures 7 and 8).

Table 1. MS Excel worksheet used to compute stream flow volume from manual measurements.

\begin{tabular}{lllllll}
\hline Point & Distance (ft) & Depth $(\mathbf{f t})$ & Velocity $(\mathbf{f t} / \mathbf{s e c})$ & Section Width $(\mathbf{f t})$ & Section area $\left(\mathbf{f t}^{2}\right)$ & Change in Flow, $\Delta \mathbf{Q}\left(\mathbf{f t}^{3} / \mathbf{s e c}\right)$ \\
\hline 1 & 0.00 & 0.00 & 0.00 & 0.25 & 0.00 & 0.00 \\
2 & 0.5 & 0.35 & 0.00 & 0.50 & 0.18 & 0.00 \\
3 & 1.00 & 0.36 & 0.00 & 0.50 & 0.18 & 0.00 \\
4 & 1.50 & 0.33 & 0.05 & 0.50 & 0.17 & 0.01 \\
5 & 2.00 & 0.34 & 0.27 & 0.50 & 0.17 & 0.05 \\
6 & 2.50 & 0.36 & 0.16 & 0.50 & 0.18 & 0.03 \\
7 & 3.00 & 0.33 & 0.32 & 0.50 & 0.17 & 0.05 \\
8 & 3.50 & 0.4 & 0.46 & 0.50 & 0.20 & 0.09 \\
9 & 4.00 & 0.36 & 0.23 & 0.50 & 0.18 & 0.04 \\
10 & 4.50 & 0.37 & 0.13 & 0.50 & 0.19 & 0.02 \\
11 & 5.00 & 0.45 & 0.05 & 0.50 & 0.23 & 0.01 \\
12 & 5.50 & 0.21 & 0.00 & 0.50 & 0.11 & 0.00 \\
13 & 6.00 & 0.34 & 0.00 & 0.50 & 0.17 & 0.00 \\
14 & 6.50 & 0.25 & 0.00 & 0.50 & 0.13 & 0.00 \\
15 & 7.00 & 0.16 & 0.00 & 0.55 & 0.09 & 0.00 \\
16 & 7.60 & 0.00 & 0.00 & 0.30 & 0.00 & 0.00 \\
\hline
\end{tabular}

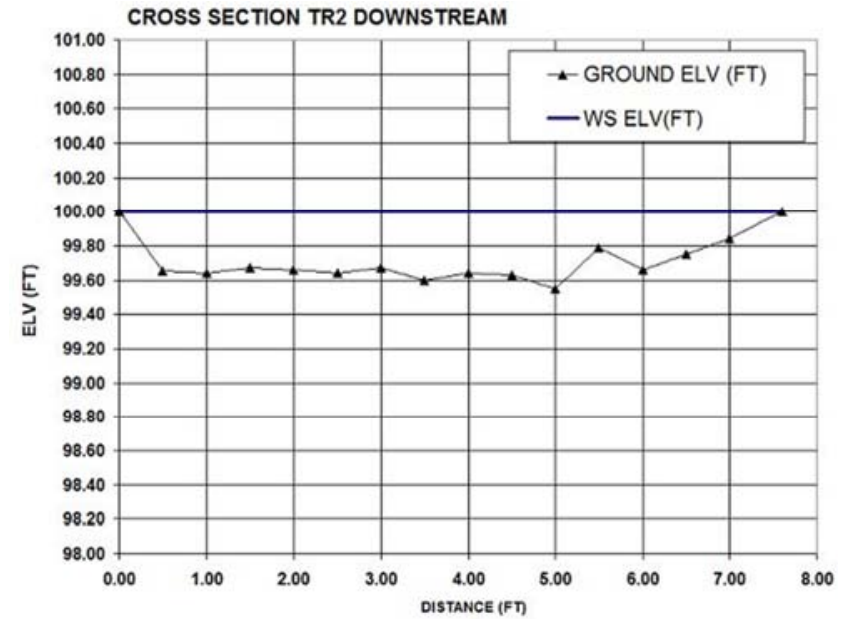

Figure 7. Manually obtained water depth at 6-inch intervals across the stream. The water surface is indicated by the blue line. Elevations are in feet above mean sea level at the site.

\section{Results}

\subsection{Stage Curve}

One of the primary goals of the WERI Toguan River project was to establish the rating curve for the Toguan River near the site of the WWTP effluent discharge point into the stream. The manually obtained flow measurements and manual and electronic measurements of the water level were used to plot the stage height (y-axis) versus the flow volume seen in Figure 8. The manual measurements of the flow were quite labor intensive, involving a nearly one-hour drive to the site by two or three project participants, with about one-hour needed to perform the flow measurements. After acquiring several manual flow measurements, it became clear that most of the flow measurements would capture near base-level flow (notice the cluster of dots at low stream level and low flow in Figure 8). It thus became more imperative to acquire flow measurements during or shortly after heavy rainfall events.

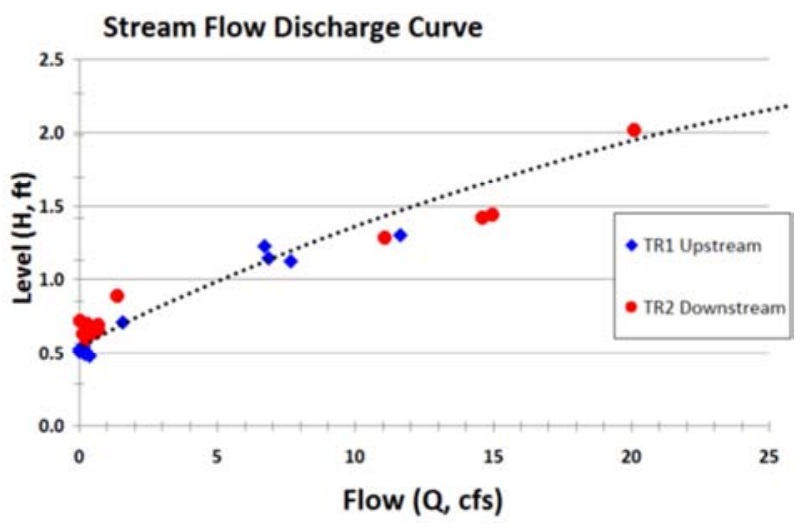

Figure 8. Preliminary Stage Curve, Toguan River sites TR1 and TR2.

Based on weather patterns, the team made a good-faith effort to measure the streamflow as soon as possible after heavy rainfall events. Because of El Niño, the weather became unusually dry from January through July 2016. Ironically the highest flow was captured right at the start of the project during a heavy rainfall event of 28 December 2015, when 2.11 inches of rainfall occurred in the watershed in less than 2 hours. Two of the WERI project team members drove to the site at the commencement of very heavy rainfall around noon on the 28th. After a careful journey south through downpours and flooded roads, the team entered the river just as the rainfall had ended. Water was knee deep and it was almost impossible to stand in the stream to take the measurements. During the 20 minutes needed to obtain the flow measurements at site TR-1, the stream level visibly fell by about 6 inches, before the team made its way to site TR-2 to obtain flow measurements there. Thus, the difference between the flows at sites TR-1 and TR-2 (one upstream and the other downstream of the discharge point) could not be used to assess the amount of flow entering the stream from the discharge channel (one of the secondary goals of the project).

At the TR-2 measuring site, the cross section of the stream 
is roughly trapezoidal (Figure 9). A taut line stretched horizontally between two trees, one each on either stream bank, was used as the benchmark for the measurements shown in this figure. The north side of the stream at site TR-2 (left side on Figure 9) is bounded by a very steep wall that continues upward for several more feet. On the right side, beyond the 25 -foot mark, there is a gently sloping flood plain continuing for at least another 10 feet before a steep rise begins. With a trapezoidal profile up to the benchmark " 0 ", the flow volume would theoretically be expected to behave as an ideal flow in a trapezoidal open channel (see section 5a for an analytical solution). Above the benchmark "0", any increase of flow would spread across the small flood plain, so that more flow could be handled than otherwise. This is discussed in the section on the analytical flow solution. Stream stage height during times of manual acquisition of flow velocities never exceeded -40 inches below the benchmark, or a 2-foot stream depth.

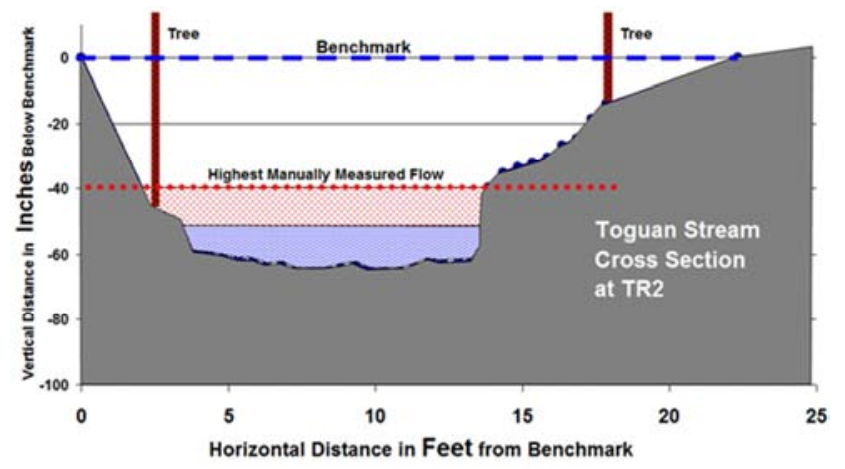

Figure 9. A cross section of the Toguan Stream at the TR-2 measuring site. The benchmark " 0 " was arbitrarily set at the location of a rope stretched taut between two trees. The highest measured flow during the study period was obtained on 28 December 2015 when the stream stage height (red dotted line) was at -40 inches below the " 0 " benchmark (blue dashed line).

\subsection{River Stage Height Versus 1-Hour Prior Rainfall}

The continuous measurement of stream depth by the level loggers and the continuous measurement of the rainfall in the watershed, allowed for the development of relationships between heavy rainfall and stream stage height (Figure 10). Over the course of the study period, 17 heavy rainfall events were used to construct Figure 10. The rainfall in the 1-hour period prior to each of 17 spikes of water level was plotted against the peak level recorded by the level loggers. On the heavy rainfall event of 28 December 2015, the level loggers indicated that the stage height reached just under 3 feet at 4:15 PM. The WERI team arrived on-site at about this time and were at first unable to enter the river because the water level was too high for manual entry. At 4:40 PM, the water level had dropped substantially to 2 feet, and the team entered the river to acquire the depth and flow measurements needed for the flow volume calculation (Figure 8).

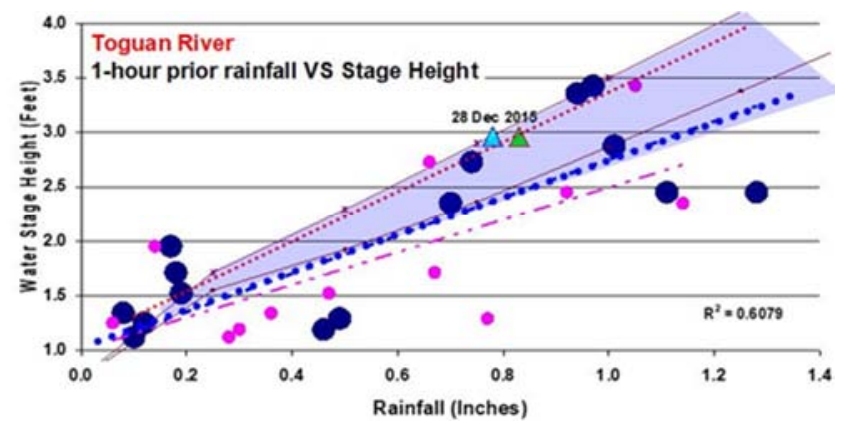

Figure 10. The stage height of the Toguan River versus the 1-hour prior rainfall. The dotted red line is the most conservative estimate, providing the highest stage height for a given amount of prior heavy rainfall. The blue and green triangles show the 28 December 2015 event during which the flow volume was manually measured.

\section{Discussion}

1. Refinements to the Stream Flow Discharge Curve

Since the Toguan river project was undertaken during a dry year, there are only a handful of heavy rain events to examine. Also, the manual readings of flow velocity and depth, contain mostly redundant readings of conditions at base flow. There were only four manual readings taken during elevated streamflow immediately following heavy rainfall events. The highest flow volume manually sampled was on December 28, 2015, almost immediately following a heavy rainfall event on that day.

Various methods are available to estimate the discharge curve [9-12]. Since a continuous measurement of stream stage was obtained using the electronically recording level loggers, another method was available to obtain an estimate of the discharge curve. An interactive tool for the calculation of open channel flow is available on the internet [8]. Using the measured cross section of the stream and other physical parameters of the stream, the web-based tool [8] can be used to calculate the flow volume.

Using the web-based tool, one first must choose the basic shape of the stream cross section [8]. A trapezoid was chosen for the Toguan river at our measured site. The measurements of the indicated perimeter sections of the trapezoid are entered (including the stream depth) along with the roughness parameter, " $n$ ". After the parameters are entered, the utility computes the flow volume and some other physical properties of the stream flow such as the Froude number. By stepping the calculation at intervals of 0.25 feet depth, the "theoretical" rating curves for the flow volume versus depth are obtained for Figure 11. The parameters entered into the web-based tool were adjusted so that the resulting calculations of the flow through a stage depth of 2 feet matched the measured values.

Another theoretical curve was chosen to yield about a 25\% higher flow volume for a given stage height (light green line). The higher-flow light green curve, while staying just on the high (right) side of the in-situ measurements of the flow, provides a margin of safety for flow estimates. 


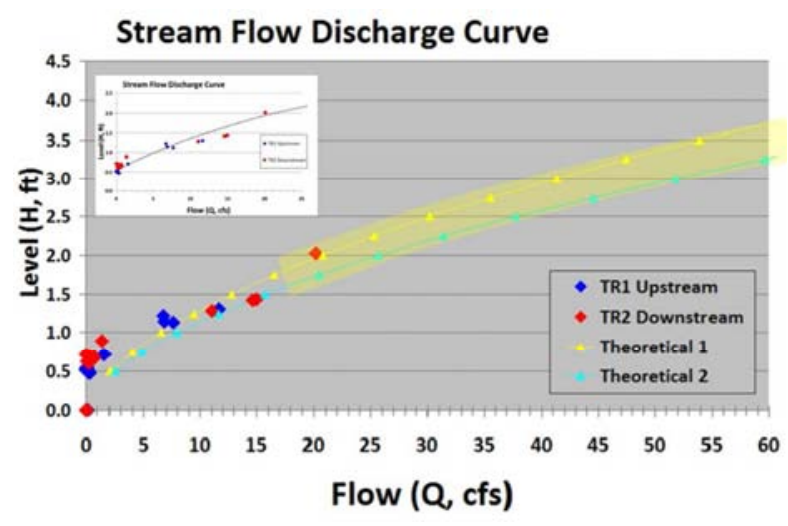

Figure 11. The flow discharge curve for the Toguan River combining the manually measured flow with two calculations of the flow using the webbased open channel flow calculator [8].

2. Stream Stage Height Short-term Prediction Using a Routing Model

River stage data has been extensively used in flood modelling applications [13-16]. The stage height patterns of Toguan River indicate that it is very flashy. After a large pulse of rain over a 15 -minute period, it takes about 20 minutes for the stream height to reach its peak. It then falls away at a rate defined with an e-folding time of about 2.4 hours. Using a two-path routing model (Figure 12), a shortterm prediction of stream stage height can be made using the rainfall as a predictor (Figure 12). In this model, each 15- minute rainfall is partitioned and placed into two hypothetical storage reservoirs: one to store the rainfall and deliver runoff to the stream at a "fast" rate, and the other to store the rainfall and deliver runoff to the stream at a "slow" rate. With appropriate scaling, a realistic stream stage was obtained (Figure 13). The e-folding time scale for the "fast" flow was about 1.5 hours, and the e-folding time scale for the slow flow was about 6 hours. Without the addition of a "slow" flow component, the model prediction always fell back too quickly to the base flow condition. With real-time rainfall information, the model could thus yield a continual 20minute advance estimate of stage height.

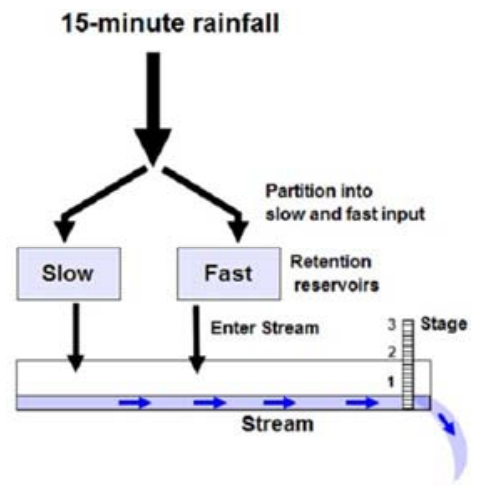

Figure 12. Schematic of the routing model used to predict the stream stage height given the rainfall in the half-hour prior to the peak flow.

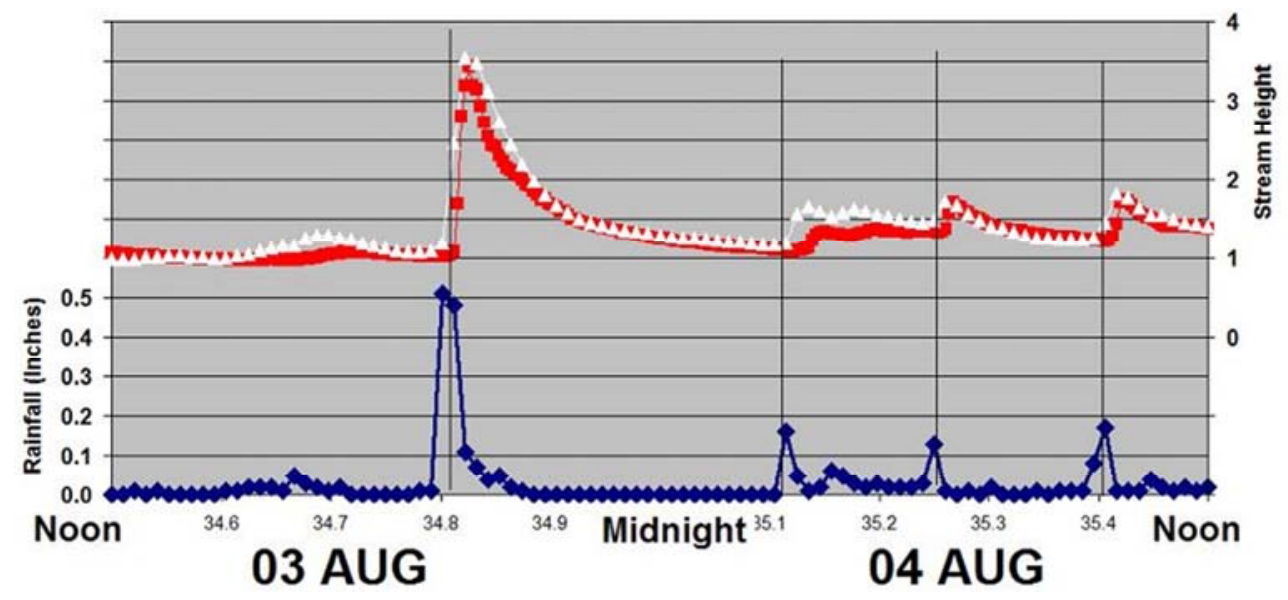

Figure 13. A prediction of stream stage height during the course of a heavy rainfall during the 24 hours from noon on 03 August to noon of 04 August (2016). The dark blue curve is rainfall at 15-minute intervals. The red curve is the measured stream stage, and the white curve is the stage height predicted by the routing model.

\section{Conclusions}

Throughout the project period, the research team obtained continual measurements of rainfall and stream water depth. Several manual measurements of flow volume were acquired-most of these during nominal base-flow conditions. Because of El Niño drought and a peculiar night-time timing of most storms, only four manual measurements of flow were made during storm-elevated conditions. These higher-flow measurements form the backbone of the rating curve. In order to buttress the rating curve derived from the manual measurements, a rating curve was computed analytically by entering measured stream physical properties (e.g., channel slope and profile) into a web-based open-channel flow calculation utility [8]. The analytical flow calculations were loosely anchored to the manual flow measurements and then extended to stream stage heights of 5 feet.

Conditions were far more favorable for the collection of the time series of stream stage height by the level loggers and the continual measure of the rainfall by the on-site rain gauge. These instruments performed flawlessly! The chart of stage height versus 1-hour prior rainfall (Figure 10) is derived from all 17 significant rainstorms that occurred 
during the project period. As a bonus, a simple two-pathway routing model was used to make short-term predictions of stream stage height.

For future work, it is recommended to capture more storm events. A few more flow velocity measurements acquired during storm-elevated flow would help to increase the confidence of the rating curve that was derived during the study project period. A continued benefit of the study is that it established a baseline for the hydrologic properties of the Toguan watershed that can be used to assess the impact of any future improvements in the existing wastewater treatment plant operations or other significant developments within this watershed.

\section{Acknowledgements}

We would like to express our appreciation and thanks to our graduate students at UOG Environmental Science Program, Lauren Swaddell and Bill Whitman, for their assistance in equipment installation, data collection and analysis. We thank Mr. Clint Simpson for his help in the field (carrying gear, cutting trail and other logistical support), and the crew from Brown and Caldwell who helped in site selection and watershed mapping. Special thanks to Mr. Paul Kemp and Ms. Vangie Lujan from Guam Water Works Authority (GWA) for their project interest and providing financial support. Any findings or conclusions made in this paper do not necessarily reflect the opinion or final analysis of the funding agencies.

\section{References}

[1] Mujeriego, R., \& Asano, T. (1999). The role of advanced treatment in wastewater reclamation and reuse. Water Science and Technology, 40 (4-5), 1.

[2] Garbowski, T., Wiśniewski, J., \& Bawiec, A. (2018). Analysis and Assesment of the Wastewater Treatment Plant Operation in the City of Kłodzko. Journal of Ecological Engineering, 19 (2).

[3] Kouloumbis, P., Rigas, F., \& Mavridou, A. (2000). Environmental problems from the disposal of sewage sludge in Greece. International Journal of Environmental Health Research, 10 (1), 77-83.

[4] Wen, Y., Khosrowpanah, S., \& Heitz, L. F. (2009). Watershed Land Cover Change in Guam. Water and Environmental Research Institute of the Western Pacific, University of Guam.
[5] Hoot, W. (2018). Guam Coral Reef Initiative. 2018. Guam Coral Reef Resilience Strategy. 69 pp.

[6] Shelton III, A. J., \& Richmond, R. H. (2016). Watershed restoration as a tool for improving coral reef resilience against climate change and other human impacts. Estuarine, Coastal and Shelf Science, 183, 430-437.

[7] Brown and Caldwell (2018). Water resources master plan update volume 1 overview and fundamentals: final August 2018. Prepared for Guam Waterworks Authority, Mangilao, Guam by Brown and Caldwell, Guam, 440 pp.

[8] Fang, X. (2000). The open channel flow calculator. Retrieved from https://www.eng.auburn.edu/ xzf0001/Handbook/Channels.html.

[9] Ferguson, R. I. (1987). Accuracy and precision of methods for estimating river loads. Earth surface processes and landforms, $12(1), 95-104$.

[10] Baldassarre, G. D., \& Montanari, A. (2009). Uncertainty in river discharge observations: a quantitative analysis. Hydrology and Earth System Sciences, 13 (6), 913-921.

[11] Birkinshaw, S. J., Moore, P., Kilsby, C. G., O'donnell, G. M., Hardy, A. J., \& Berry, P. A. M. (2014). Daily discharge estimation at ungauged river sites using remote sensing. Hydrological Processes, 28 (3), 1043-1054.

[12] Moftakhari, H. R., Jay, D. A., \& Talke, S. A. (2016). Estimating river discharge using multiple-tide gauges distributed along a channel. Journal of Geophysical Research: Oceans, 121 (4), 2078-2097.

[13] Ettritch, Georgina, Andy Hardy, Landing Bojang, Dónall Cross, Peter Bunting, and Paul Brewer (2018). Enhancing digital elevation models for hydraulic modelling using flood frequency detection. Remote sensing of environment, 217: 506-522.

[14] Mahmood, M. N., Schmidt, C., Fleckenstein, J. H., \& Trauth, N. (2019). Modeling the Impact of Stream Discharge Events on Riparian Solute Dynamics. Groundwater, 57 (1), 140-152.

[15] Phillips, J. D. (2015). Hydrologic and geomorphic flow thresholds in the Lower Brazos River, Texas, USA. Hydrological sciences journal, 60 (9), 1631-1648.

[16] Dobriyal, P., Badola, R., Tuboi, C., \& Hussain, S. A. (2017). A review of methods for monitoring streamflow for sustainable water resource management. Applied Water Science, 7 (6), 2617-2628. 